\title{
Sinais e sintomas manifestados por pacientes em cuidados paliativos oncológicos na assistência domiciliar: uma revisão integrativa
}

\author{
Signs and symptoms manifested by patients in palliative cancer care in homecare: integrative review \\ Signos y síntomas manifestados por pacientes en cuidados oncológicos paliativos en atención \\ domiciliaria: una revisión integradora
}

\author{
Nair Caroline Cavalcanti de Mendonça \\ Bittencourt ${ }^{1}$ (1) \\ Karoliny Alves Santos ${ }^{1}$ (1) \\ Maria Gefé da Rosa Mesquita ${ }^{1}$ (B) \\ Vanessa Gomes da Silva² \\ Audrei Castro Telles ${ }^{2}$ (1) \\ Marcelle Miranda da Silva ${ }^{1}$ (D)
}

1. Universidade Federal do Rio de Janeiro, Escola de Enfermagem Anna Nery. Rio de Janeiro, RJ, Brasil.

2. Instituto Nacional de Câncer José Alencar Gomes da Silva, Hospital do Câncer IV. Rio de Janeiro, RJ, Brasil.
Autor correspondente:

Marcelle Miranda da Silva.

E-mail: marcellemsufrj@gmail.com.

Recebido em 07/12/2020.

Aprovado em 01/05/2021.

DOI:https://doi.org/10.1590/2177-9465-EAN-2020-0520

\begin{abstract}
REsUMO
Objetivo: identificar os principais sinais e sintomas manifestados por pacientes em cuidados paliativos oncológicos na assistência domiciliar. Método: revisão integrativa nas bases LILACS, MEDLINE e CINAHL em janeiro de 2020. Perguntouse: "Quais os principais sinais e sintomas manifestados por pacientes em cuidados paliativos oncológicos destacados nos estudos abrangendo o contexto do domicílio?". Foram descritores/termos: Sinais e Sintomas/Signs and Symptoms; Assistência Domiciliar/Home Care Services; Cuidados Paliativos/Palliative Care e Neoplasias/Neoplasms. Elencaram-se como critérios de elegibilidade: texto completo; entre 2015 e 2019; em inglês, português ou espanhol e idade adulta. Para o mapeamento dos dados, consideraram-se: título; país; ano; objetivo; método; sinais e sintomas. Os resultados foram categorizados em subgrupos, considerando a classificação conceitual predeterminada (sinal e sintoma). O elemento contagem facilitou a análise e a comparação de dados. Resultados: foram selecionados 35 artigos, sendo identificados 25 sinais e 23 sintomas Os mais frequentes foram: dor, náusea/vômito, dispneia, fadiga, depressão, ansiedade, constipação, perda de apetite, sonolência, bem-estar e insônia. A maioria (39) relacionou-se ao domínio físico. Conclusão: a identificação dos principais sinais e sintomas, neste contexto, direciona a prática dos profissionais de saúde para as intervenções mais adequadas e o mais precocemente possível, contribuindo para viabilizar a assistência domiciliar, e alerta para a necessidade de educação permanente sobre este tema.
\end{abstract}

Palavras-chave: Sinais e Sintomas; Cuidados Paliativos; Neoplasias; Assistência Domiciliar; Revisão.

\section{Abstract}

Objective: to identify the main signs and symptoms manifested by palliative care oncology patients in home care. Method: integrative review in LILACS, MEDLINE and CINAHL databases in January 2020. The question was asked: "What are the main signs and symptoms manifested by patients in palliative oncology care highlighted in studies covering the context of the home?" Descriptors/terms were: Signs and Symptoms/Signs and Symptoms; Home Care/Home Care Services; Palliative Care/Palliative Care and Neoplasms/Neoplasms. Eligibility criteria were listed as follows: full text; between 2015 and 2019; in English, Portuguese or Spanish and adult age. For data mapping, the following were considered: title; country; year; objective; method; signs and symptoms. The results were categorized into subgroups, considering the predetermined conceptual classification (sign and symptom). The counting element facilitated the analysis and comparison of data. Results: a total of 35 articles were selected, and 25 signs and 23 symptoms were identified. The most frequent were: pain, nausea/vomiting, dyspnea, fatigue, depression, anxiety, constipation, loss of appetite, sleepiness, well-being, and insomnia. Most (39) were related to the physical domain. Conclusion: the identification of the main signs and symptoms, in this context, directs the practice of health professionals to the most appropriate interventions as early as possible, contributing to the feasibility of home care, and alerts to the need for continuing education on this topic.

Keywords: Signs and Symptoms; Palliative Care; Neoplasms; Home Nursing; Review.

\section{Resumen}

Objetivo: identificar los principales signos y síntomas que manifiestan los pacientes en cuidados oncológicos paliativos en la atención domiciliaria. Método: revisión integradora basada en LILACS, MEDLINE y CINAHL en enero de 2020. Se preguntó: “¿Cuáles son los principales signos y síntomas que manifiestan los pacientes en cuidados paliativos oncológicos destacados en estudios que abarcan el contexto del hogar?". Los descriptores / términos fueron: signos y síntomas / /Signs and Symptoms; Asistencia domiciliaria / Home Care Services; Cuidados paliativos / Palliative Care / y Neoplasias/ Neoplasms. Se enumeraron los siguientes criterios de elegibilidad: texto completo; entre 2015 y 2019; en inglés, portugués o español y edad adulta. Para el mapeo de datos, se consideraron los siguientes: título; padres; año; objetivo; método; signos y síntomas. Los resultados se categorizaron en subgrupos, considerando la clasificación conceptual predeterminada (signo y síntoma). El elemento de conteo facilitó el análisis y la comparación de datos. Resultados: Se seleccionaron 35 artículos, se identificaron 25 signos 
y 23 síntomas. Los más frecuentes fueron: dolor, náuseas / vómitos, disnea, fatiga, depresión, ansiedad, estreñimiento, pérdida de apetito, somnolencia, bienestar e insomnio. La mayoría (39) estaban relacionados con el dominio físico. Conclusión: la identificación de los principales signos y síntomas, en este contexto, orienta la práctica de los profesionales de la salud hacia las intervenciones más adecuadas y lo más temprano posible, contribuyendo a hacer factible la atención domiciliaria, y alerta sobre la necesidad de una educación permanente sobre este tema.

Palabras-clave: Signos y Síntomas; Cuidados Paliativos; Neoplasias; Cuidado domiciliario.

\section{INTRODUÇÃO}

As Doenças e Agravos Não Transmissíveis (DANT) são as principais causas de adoecimento e óbito da população, com destaque para o câncer. No Brasil, estima-se, para o triênio 2020-2022, a ocorrência de 625 mil casos novos de câncer em cada ano e, devido às elevadas taxas de morbimortalidade desta doença, seu diagnóstico é estigmatizado, trazendo consigo a ideia de sofrimento e morte, apesar da possibilidade de cura' ${ }^{1}$.

Em consequência do câncer avançado, há sinais e sintomas incapacitantes, como dor e outros problemas de natureza física, psicossocial e espiritual. Nesse contexto, para auxiliar no manejo dos sinais e sintomas, a fim de promover conforto e qualidade de vida, indica-se a integração dos Cuidados Paliativos (CP) às metas de tratamento o quanto antes ${ }^{2}$. Uma vez esgotadas as medidas para o controle da doença, deve prevalecer a assistência especializada dos Cuidados Paliativos Exclusivos (CPE), a qual está pautada na integralidade, na interdisciplinaridade e no binômio paciente/família ${ }^{3}$.

Os CP podem ser oferecidos em diferentes cenários, desde unidades hospitalares, em consultas ambulatoriais ou no domicílio, de acordo com critérios previamente estabelecidos. Em modelos assistenciais de CPE, a Assistência Domiciliar (AD) é a modalidade de atendimento diferencial, indicada aos pacientes com funcionalidade comprometida, ou seja, àqueles com dificuldade ou que já não conseguem se locomover, contribuindo para o conforto e a qualidade de vida, uma vez que permite, ao paciente, o convívio em família, uma maior autonomia e menor risco de infecções ${ }^{4}$.

Todavia, a AD requer maior apoio e participação da família, que deve considerar a possibilidade iminente de morte no domicílio. Nesse sentido, é indispensável reconhecer e manejar adequadamente os sinais e sintomas, uma vez que sentimentos como o medo da morte podem exacerbá-los, levando a pessoa ou sua família a optar pela hospitalização, marcando os últimos dias de vida com recorrentes admissões nas emergências, internações e morte no ambiente hospitalar. A avaliação criteriosa e o controle dos sinais e sintomas como meta principal na AD auxiliam nos indicadores de qualidade da assistência e de morte no domicílio, bem como na indicação mais apropriada da internação hospitalar do paciente em $\mathrm{CPE}^{5}$.

A avaliação abrangente dos sinais e sintomas é a base para um tratamento paliativo individualizado e eficaz e, para que a morte seja digna, é fundamental que o paciente receba conforto, apesar das limitações, e que tenha a sua autonomia respeitada ${ }^{6}$.

Para o sucesso da gestão do cuidado e seguimento do paciente e sua família no domicílio, há a necessidade de atenção à leitura dos sinais e sintomas e sua rápida mudança associada à doença e ao paciente ${ }^{7}$.

Desse modo, objetivou-se identificar os principais sinais e sintomas manifestados por pacientes em cuidados paliativos oncológicos na assistência domiciliar.

\section{MÉTODO}

Trata-se de uma Revisão Integrativa da Literatura (RIL) que seguiu as seguintes etapas: formulação da questão de pesquisa e do objetivo; pesquisa na literatura (estabelecimento dos critérios de inclusão e exclusão, uso de bases de dados e seleção dos estudos); categorização dos estudos (extração, organização e sumarização das informações e formação do banco de dados); avaliação dos estudos incluídos na revisão (a partir dos critérios de inclusão e exclusão previamente estabelecidos e da análise dos estudos selecionados); interpretação dos resultados e síntese do conhecimento ${ }^{8}$.

Para a construção da questão de pesquisa, aplicou-se o acrônimo PICo (população, fenômeno de interesse e contexto) em que: a população é representada pelos pacientes em cuidados paliativos oncológicos; o fenômeno de interesse compreende os sinais e sintomas e o contexto envolve a assistência domiciliar ${ }^{9}$. Assim, tem como questão: "Quais os principais sinais e sintomas manifestados por pacientes em cuidados paliativos oncológicos destacados nos estudos abrangendo o contexto do domicílio?".

A busca via Portal de Periódicos da Coordenação de Aperfeiçoamento de Pessoal de Nível Superior (CAPES) foi desenvolvida nas bases: Literatura Latino-Americana e do Caribe em Ciências da Saúde (LILACS $\AA$ ); Public Medline (PubMed $\AA$ ) e Cumulative Index to Nursing \& Allied Health Literature (CINAHL $®$ ).

Aplicaram-se diferentes estratégias de busca para cada base. Porém, apresenta-se, no Quadro 1, apenas a estratégia aplicada na CINAHL. As demais estratégias de busca poderão ser disponibilizadas de forma completa por meio de contato com a autora correspondente via correio eletrônico.

A busca nas bases de dados foi realizada em janeiro de 2020 por duas pesquisadoras alunas de pós-graduação Stricto sensu, que foram treinadas para realizar a pesquisa de forma independente, seguindo os mesmos critérios. Uma discussão em grupo, com a participação de uma terceira pesquisadora, foi realizada para a avaliação crítica dos artigos elegíveis e consenso final da seleção para a revisão.

Como critérios de elegibilidade, aplicaram-se os filtros: textos completos disponíveis em revistas acadêmicas; publicados entre 2015 e 2019; nos idiomas inglês, português ou espanhol e idade adulta. O uso do filtro relacionado à idade deveu-se à experiência das pesquisadoras em cuidados paliativos ao paciente adulto. 
Quadro 1. Estratégias de busca para a base de dados CINAHL. Rio de Janeiro, Brasil, 2020.

\begin{tabular}{|c|}
\hline CIN \\
\hline 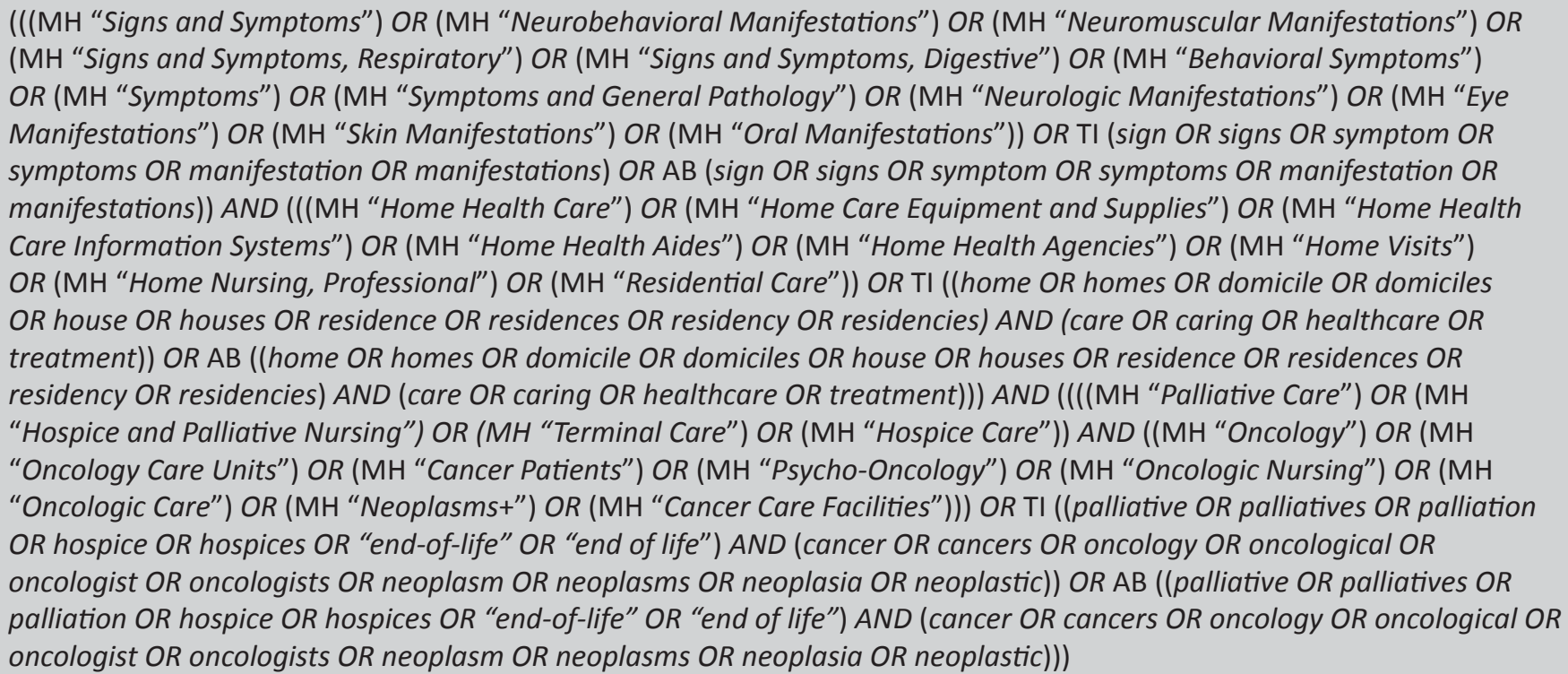 \\
\hline
\end{tabular}

Fonte: dados da pesquisa.

E o recorte temporal justificou-se pela necessidade de revisar o tema com base na atualidade.

Excluíram-se os artigos que não respondiam à questão de pesquisa e os editorais. Não foram realizadas exclusões por critério de grau de recomendação dos estudos, uma vez que o cálculo de escore de qualidade não é recomendado para a RIL devido à multiplicidade dos métodos dos estudos primários selecionados ${ }^{10}$. A avaliação dos estudos incluídos procedeuse a partir dos critérios de inclusão e exclusão previamente estabelecidos, o enquadramento realizado com rigor a partir da leitura dos títulos e resumos e/ou a leitura na íntegra dos estudos elegíveis.

O mapeamento dos dados foi realizado após a definição das informações que deveriam ser extraídas dos artigos selecionados. Para este estudo, foram consideradas as informações: título; país; ano da publicação; objetivo; método e sinais e sintomas mencionados.

Para a análise, aplicou-se a categorização dos resultados em subgrupos, considerando-se a classificação conceitual predeterminada, no caso, referente ao sinal como um dado objetivo e verificável e ao sintoma como um dado subjetivo, que depende da verbalização do paciente ou de qualquer outra forma de manifestação não verbal ${ }^{11}$.

A exibição dos dados em gráficos e tabelas foi empregada para melhorar a visualização de padrões e relacionamentos dentro e entre as fontes de dados primários, assumindo o lugar de ponto de partida para a interpretação. Os sinais e sintomas foram registrados em planilha do Microsoft Excel $\circledast$ e ordenados de acordo com o número de vezes em que foram mencionados, pelo menos, uma vez em cada artigo. Deste modo, o elemento contagem foi a estratégia empregada para facilitar a análise e a comparação de dados ${ }^{10}$. Utilizou-se o software EndNote ${ }^{x 9}$ para o gerenciamento das referências.

\section{RESULTADOS}

A Figura 1 ilustra o número de fontes de evidências selecionadas, traçando o fluxo de seleção da amostra de acordo com os critérios de elegibilidade e os motivos das exclusões.

Dos 35 artigos selecionados, sete (20\%) foram publicados na Itália, cinco (14,3\%), nos Estados Unidos da América, cinco $(14,3 \%)$, no Brasil, três $(8,6 \%)$, na Alemanha e três $(8,6 \%)$, no Japão. No Canadá e Reino Unido, foram publicados dois $(5,7 \%)$ em cada país. Em cada um dos países, como Egito, França, Holanda, Polônia, África do Sul, China, Chile e Taiwan, foi publicado um artigo (2,85\%).

O Quadro 2 apresenta o mapeamento das características dos 35 artigos selecionados. Dentre os 48 sinais e sintomas mencionados nos artigos, os mais citados, em ordem decrescente em número de vezes, foram: dor (34); náusea/vômito (22); dispneia (21); fadiga/fraqueza/astenia (21); depressão (19); perda de apetite/anorexia (17); constipação (15); ansiedade (14); sonolência (12); bem-estar (11) e insônia (10) (Figura 2).

De acordo com a classificação conceitual predeterminada adotada neste estudo, foram mencionados 25 (52\%) sinais e 23 (48\%) sintomas (Quadro 3). Observa-se a maior menção aos sinais e sintomas de ordem física. Destaca-se que, dos 48 sinais e sintomas, exceto o bem-estar, que reúne diferentes domínios, 39 (83\%) estiveram relacionados ao domínio físico e oito (17\%), ao domínio psicoemocional e ao desempenho cognitivo. 


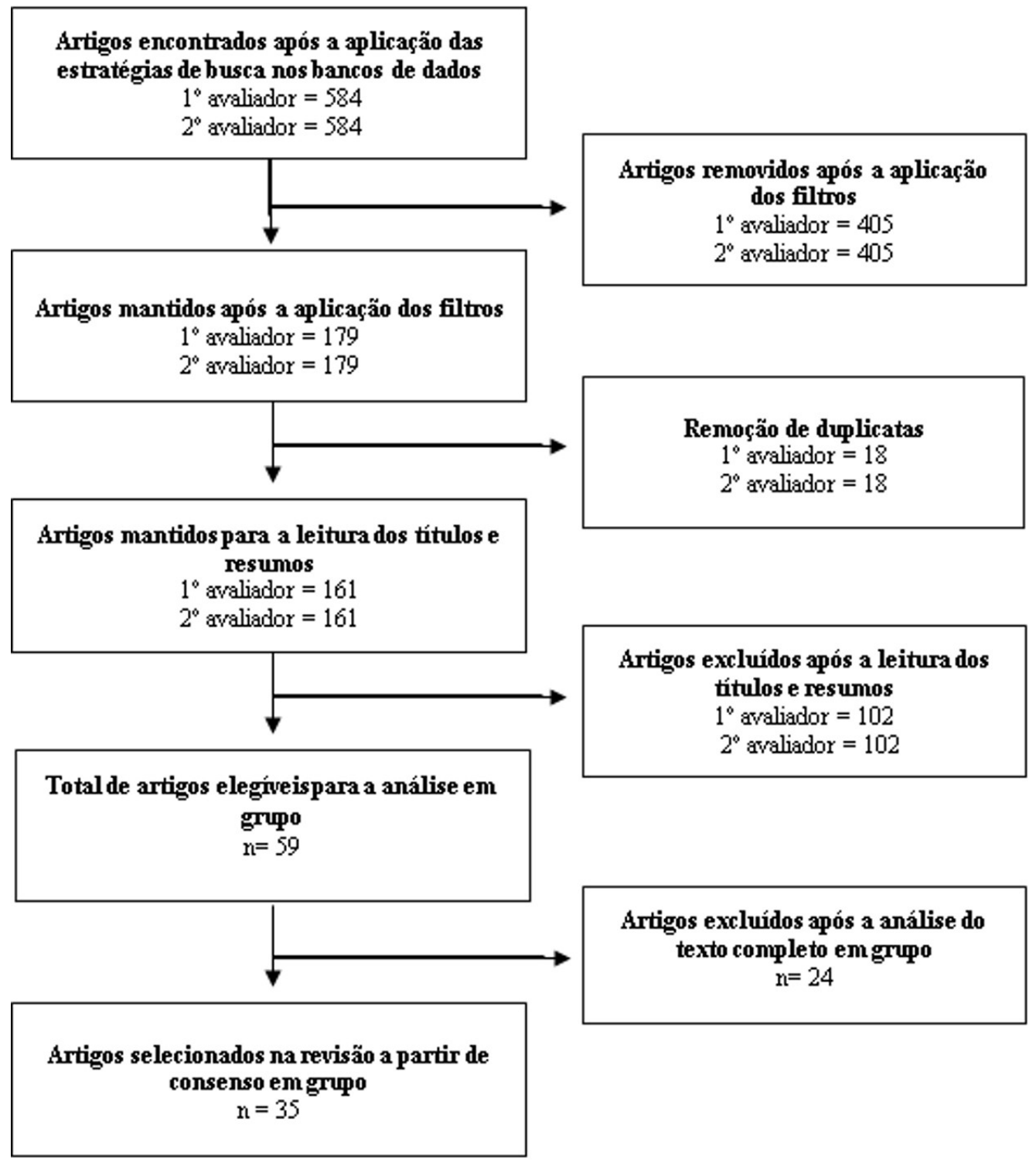

Figura 1. Fluxo do processo de seleção dos artigos que se relacionaram com a questão e o objetivo desta revisão. Rio de Janeiro, Brasil, 2020.

Fonte: Dados da pesquisa.

Quadro 2. Mapeamento das características dos 35 artigos selecionados. Rio de Janeiro, Brasil, 2020.

\begin{tabular}{|c|c|c|c|c|}
\hline Título & Ano/País & Objetivo (s) & Método & $\begin{array}{c}\text { Principais sinais e } \\
\text { sintomas relacionados à } \\
\text { doença oncológica }\end{array}$ \\
\hline
\end{tabular}

Fonte: Dados da pesquisa. 
Quadro 2. Continuação...

\begin{tabular}{|c|c|c|c|c|}
\hline Título & Ano/País & Objetivo (s) & Método & $\begin{array}{c}\text { Principais sinais e } \\
\text { sintomas relacionados à } \\
\text { doença oncológica }\end{array}$ \\
\hline $\begin{array}{l}\text { How much psychological } \\
\text { distress is experienced at } \\
\text { home by patients with } \\
\text { palliative care needs } \\
\text { in Germany? A cross- } \\
\text { sectional study using the } \\
\text { distress thermometer }{ }^{13}\end{array}$ & 2017/ Alemanha & $\begin{array}{l}\text { Descrever a prevalência } \\
\text { de sofrimento psicossocial } \\
\text { em pacientes em cuidados } \\
\text { paliativos que vivem em casa } \\
\text { e os fatores relacionados e } \\
\text { testar a implementação do } \\
\text { Termômetro de Emergência no } \\
\text { serviço domiciliar de cuidados } \\
\text { paliativos. }\end{array}$ & $\begin{array}{l}\text { Estudo } \\
\text { prospectivo e } \\
\text { transversal }\end{array}$ & $\begin{array}{l}\text { Medo, nervosismo, } \\
\text { tristeza, constipação, } \\
\text { fadiga, dispneia, } \\
\text { alterações na micção, } \\
\text { dor, insônia, memória/ } \\
\text { concentração, apetite, } \\
\text { inchaço, diarreia, } \\
\text { indigestão, náusea, nariz } \\
\text { seco/congestionado, } \\
\text { sono, pele seca/com } \\
\text { coceira, formigamento } \\
\text { nas mãos/pés e angústia. }\end{array}$ \\
\hline $\begin{array}{l}\text { Palliative home care for } \\
\text { patients with advanced } \\
\text { haematological } \\
\text { malignancies-a } \\
\text { multicenter survey }{ }^{14}\end{array}$ & 2017/ Alemanha & $\begin{array}{l}\text { Analisar os sintomas físicos } \\
\text { e as demandas psicossociais } \\
\text { de pacientes com doença } \\
\text { hematológica avançada } \\
\text { sob cuidados paliativos } \\
\text { domiciliares especializados. }\end{array}$ & $\begin{array}{l}\text { Retrospectivo, } \\
\text { descritivo e } \\
\text { multicêntrico }\end{array}$ & $\begin{array}{l}\text { Dor, sangramento, fadiga, } \\
\text { depressão, dispneia, } \\
\text { náusea/vômito, edema, } \\
\text { constipação, diarreia, } \\
\text { perda de peso, disfagia, } \\
\text { hipotensão/hipertensão, } \\
\text { incontinência e } \\
\text { desidratação. }\end{array}$ \\
\hline $\begin{array}{l}\text { Prevalência de caquexia } \\
\text { neoplásica e fatores } \\
\text { associados na internação } \\
\text { domiciliar }{ }^{15}\end{array}$ & 2015/ Brasil & $\begin{array}{l}\text { Verificar quais são os fatores } \\
\text { associados à caquexia em } \\
\text { pacientes oncológicos } \\
\text { participantes de um } \\
\text { programa de internação } \\
\text { domiciliar, utilizando } \\
\text { conceitos padronizados para a } \\
\text { síndrome. }\end{array}$ & $\begin{array}{l}\text { Transversal e } \\
\text { descritivo }\end{array}$ & $\begin{array}{l}\text { Anorexia, dor, saciedade, } \\
\text { xerostomia, náuseas, } \\
\text { constipação, disfagia, } \\
\text { vômitos, disgeusia, } \\
\text { disosmia, diarreia e } \\
\text { caquexia. }\end{array}$ \\
\hline $\begin{array}{l}\text { Escala multidimensional } \\
\text { na avaliação da dor e } \\
\text { sintomas de idosos em } \\
\text { cuidados paliativos }^{16}\end{array}$ & 2016/ Brasil & $\begin{array}{l}\text { Avaliar a dor e os sintomas } \\
\text { associados em idosos com } \\
\text { câncer em cuidados paliativos } \\
\text { em domicílio. }\end{array}$ & Transversal & $\begin{array}{l}\text { Dor, cansaço, sonolência, } \\
\text { náusea, apetite, falta de } \\
\text { ar, depressão, ansiedade } \\
\text { e sensação de bem- } \\
\text { estar, prisão de ventre, } \\
\text { diarreia, incontinência } \\
\text { urinária, polaciúria, } \\
\text { insônia, anorexia e } \\
\text { fadiga. }\end{array}$ \\
\hline $\begin{array}{l}\text { Cancer patients, } \\
\text { emergencies service and } \\
\text { provision of palliative } \\
\text { care }^{17}\end{array}$ & 2016/ Brasil & $\begin{array}{l}\text { Descrever o perfil clínico e } \\
\text { sociodemográfico de pacientes } \\
\text { oncológicos atendidos na } \\
\text { emergência de um Centro } \\
\text { de Alta Complexidade em } \\
\text { Oncologia, observando a } \\
\text { cobertura dos cuidados } \\
\text { paliativos e a assistência } \\
\text { domiciliar. }\end{array}$ & Transversal & $\begin{array}{l}\text { Dor, sintomas } \\
\text { gastrointestinais e } \\
\text { respiratórios. }\end{array}$ \\
\hline
\end{tabular}

Fonte: Dados da pesquisa. 
Quadro 2. Continuação...

\begin{tabular}{|c|c|c|c|c|}
\hline Título & Ano/País & Objetivo (s) & Método & $\begin{array}{c}\text { Principais sinais e } \\
\text { sintomas relacionados à } \\
\text { doença oncológica }\end{array}$ \\
\hline $\begin{array}{l}\text { Manifestações e } \\
\text { necessidades referentes } \\
\text { ao processo de morte e } \\
\text { morrer: perspectiva da } \\
\text { pessoa com câncer }{ }^{18}\end{array}$ & 2017/ Brasil & $\begin{array}{l}\text { Conhecer as manifestações } \\
\text { e necessidades referentes ao } \\
\text { processo de morte e morrer } \\
\text { da pessoa com câncer no final } \\
\text { de vida. }\end{array}$ & $\begin{array}{l}\text { Estudo de } \\
\text { caso }\end{array}$ & $\begin{array}{l}\text { Dor, náusea/vômito, } \\
\text { constipação, anorexia, } \\
\text { dispneia, ansiedade, } \\
\text { depressão, agitação, insônia, } \\
\text { confusão, fadiga, disfagia. }\end{array}$ \\
\hline $\begin{array}{l}\text { Cognition, functionality } \\
\text { and symptoms in } \\
\text { patients under home } \\
\text { palliative care }{ }^{19}\end{array}$ & 2018/ Brasil & $\begin{array}{l}\text { Avaliar o grau de cognição, } \\
\text { funcionalidade, presença de } \\
\text { sintomas e medicamentos } \\
\text { prescritos para pacientes em } \\
\text { cuidados paliativos domiciliares. }\end{array}$ & Transversal & $\begin{array}{l}\text { Constipação, dispneia, } \\
\text { apetite, ansiedade, } \\
\text { depressão, náuseas, dor e } \\
\text { astenia. }\end{array}$ \\
\hline $\begin{array}{l}\text { Correlates and predictors } \\
\text { of changes in dyspnea } \\
\text { symptoms over time } \\
\text { among community- } \\
\text { dwelling palliative home } \\
\text { care clients }{ }^{20}\end{array}$ & 2015/ Canadá & $\begin{array}{l}\text { Descrever as características } \\
\text { clínicas e de saúde de pessoas } \\
\text { com dispneia que recebem } \\
\text { cuidados paliativos domiciliares } \\
\text { e identificar os fatores que } \\
\text { afetam a mudança na dispneia } \\
\text { ao longo do tempo. }\end{array}$ & $\begin{array}{l}\text { Coorte } \\
\text { observacional }\end{array}$ & $\begin{array}{l}\text { Dor, depressão, insônia, } \\
\text { sonolência, fadiga, } \\
\text { secreção nas vias aéreas, } \\
\text { perda de peso, edema } \\
\text { periférico, incontinência } \\
\text { urinária, incontinência } \\
\text { intestinal, refluxo ácido e } \\
\text { náuseas/vômitos. }\end{array}$ \\
\hline $\begin{array}{l}\text { Palliative care experience } \\
\text { in the last } 3 \text { months } \\
\text { of life: a quantitative } \\
\text { comparison of care } \\
\text { provided in residential } \\
\text { hospices, hospitals, } \\
\text { and the home from the } \\
\text { perspectives of bereaved } \\
\text { caregivers }^{21}\end{array}$ & 2018/ Canadá & $\begin{array}{l}\text { Capturar as experiências } \\
\text { de cuidados de fim de vida } \\
\text { em vários ambientes de } \\
\text { cuidadores enlutados de } \\
\text { pessoas que morreram em um } \\
\text { hospice residencial. }\end{array}$ & $\begin{array}{l}\text { Quantitativo e } \\
\text { descritivo }\end{array}$ & $\begin{array}{l}\text { O estudo cita a dor física } \\
\text { e "outros sintomas" de } \\
\text { forma generalizada. }\end{array}$ \\
\hline $\begin{array}{l}\text { Emergency department } \\
\text { visits at the end of life of } \\
\text { patients with terminal } \\
\text { cancer: pattern, causes, } \\
\text { and avoidability } 22\end{array}$ & 2016/Egito & $\begin{array}{l}\text { Descrever o padrão de } \\
\text { consultas de emergência, } \\
\text { explorar as suas causas e a } \\
\text { potencial evitabilidade durante } \\
\text { os últimos três meses de vida } \\
\text { de pacientes com câncer } \\
\text { terminal. }\end{array}$ & $\begin{array}{l}\text { Coorte } \\
\text { observacional }\end{array}$ & $\begin{array}{l}\text { Dor, dispneia, náusea/ } \\
\text { vômito, fadiga, } \\
\text { consciência alterada, } \\
\text { febre, sangramento, } \\
\text { diarreia, tosse, anorexia, } \\
\text { constipação, desidratação, } \\
\text { icterícia, sintomas } \\
\text { urinários, sintomas de } \\
\text { pele, edema, insônia, } \\
\text { sufocamento, agitação, } \\
\text { convulsões, disartria, } \\
\text { disfagia, rouquidão, } \\
\text { hipotensão e rinorreia. }\end{array}$ \\
\hline $\begin{array}{l}\text { Informal caregiver } \\
\text { challenges for advanced } \\
\text { cancer patients during } \\
\text { end-of-life care in } \\
\text { Johannesburg, South } \\
\text { Africa and distinctions } \\
\text { based on place of death }\end{array}$ & $\begin{array}{l}\text { 2018/ Estados } \\
\text { Unidos }\end{array}$ & $\begin{array}{l}\text { Compreender melhor os } \\
\text { desafios dos cuidadores } \\
\text { informais no final da vida } \\
\text { na África do Sul, tanto em } \\
\text { casa quanto em unidades de } \\
\text { internação. }\end{array}$ & $\begin{array}{l}\text { Estudo } \\
\text { retrospectivo } \\
\text { de coorte }\end{array}$ & $\begin{array}{l}\text { Dor, dispneia, incontinência } \\
\text { urinária, incontinência } \\
\text { fecal, insônia, prisão de } \\
\text { ventre, diarreia, fadiga, } \\
\text { fraqueza nos membros, } \\
\text { edema, febre, sede, } \\
\text { convulsões e tristeza. }\end{array}$ \\
\hline
\end{tabular}

Fonte: Dados da pesquisa. 
Quadro 2. Continuação...

\begin{tabular}{|c|c|c|c|c|}
\hline Título & Ano/País & Objetivo (s) & Método & $\begin{array}{c}\text { Principais sinais e } \\
\text { sintomas relacionados à } \\
\text { doença oncológica }\end{array}$ \\
\hline $\begin{array}{l}\text { Palliative care for } \\
\text { patients with cancer: do } \\
\text { patients receive the care } \\
\text { they consider important? } \\
\text { A survey study }\end{array}$ & $\begin{array}{l}\text { 2018/ Estados } \\
\text { Unidos }\end{array}$ & $\begin{array}{l}\text { Estudar quais os aspectos do } \\
\text { atendimento aos pacientes os } \\
\text { clínicos gerais e enfermeiros } \\
\text { de assistência domiciliar } \\
\text { consideram importantes e se } \\
\text { os pacientes recebem esses } \\
\text { aspectos. }\end{array}$ & $\begin{array}{l}\text { Quantitativo e } \\
\text { descritivo }\end{array}$ & $\begin{array}{l}\text { Dor, falta de ar, cansaço, } \\
\text { constipação, ansiedade e } \\
\text { depressão. }\end{array}$ \\
\hline $\begin{array}{l}\text { Communicating } \\
\text { caregivers' challenges } \\
\text { with cancer pain } \\
\text { management: an } \\
\text { analysis of home hospice } \\
\text { visits }^{24}\end{array}$ & $\begin{array}{l}\text { 2018/ Estados } \\
\text { Unidos }\end{array}$ & $\begin{array}{l}\text { Identificar como os } \\
\text { familiares cuidadores de } \\
\text { pacientes com câncer } \\
\text { comunicam os seus desafios } \\
\text { de gerenciamento da dor } \\
\text { aos enfermeiros durante } \\
\text { as visitas domiciliares e } \\
\text { como estes enfermeiros } \\
\text { respondem a estes desafios } \\
\text { levantados. }\end{array}$ & $\begin{array}{l}\text { Quantitativo e } \\
\text { descritivo }\end{array}$ & Dor. \\
\hline $\begin{array}{l}\text { Predictors of } \\
\text { posthospital transitions } \\
\text { of care in patients with } \\
\text { advanced cancer } 25\end{array}$ & $\begin{array}{l}\text { 2018/ Estados } \\
\text { Unidos }\end{array}$ & $\begin{array}{l}\text { Examinar os preditores do } \\
\text { local da alta e avaliar a relação } \\
\text { entre o local com a sobrevida } \\
\text { e os fatores de risco para a } \\
\text { readmissão hospitalar. }\end{array}$ & $\begin{array}{l}\text { Quantitativo e } \\
\text { descritivo }\end{array}$ & $\begin{array}{l}\text { Sistema de Avaliação de } \\
\text { Sintomas de Edmonton } \\
\text { revisado (ESAS-r) para } \\
\text { avaliar os sintomas: } \\
\text { náuseas, dispneia, } \\
\text { falta de apetite, dor, } \\
\text { sonolência, depressão, } \\
\text { ansiedade, bem-estar } \\
\text { e fadiga. Incluída a } \\
\text { constipação. }\end{array}$ \\
\hline $\begin{array}{l}\text { Home palliative sedation } \\
\text { using phenobarbital } \\
\text { suppositories: time } \\
\text { to death, patient } \\
\text { characteristics, and } \\
\text { administration protocol }^{26}\end{array}$ & $\begin{array}{l}\text { 2019/ Estados } \\
\text { Unidos }\end{array}$ & $\begin{array}{l}\text { Descrever o uso de } \\
\text { supositórios de fenobarbital } \\
\text { no domicílio para fins de } \\
\text { sedação; compreender as } \\
\text { características dos pacientes } \\
\text { em potencial e aqueles } \\
\text { em que realmente os } \\
\text { supositórios foram usados; } \\
\text { medir o tempo até a morte } \\
\text { após o início dos supositórios } \\
\text { de fenobarbital. }\end{array}$ & $\begin{array}{l}\text { Estudo série } \\
\text { de casos, } \\
\text { retrospectivo }\end{array}$ & Delírio, dor e dispneia. \\
\hline $\begin{array}{l}\text { Reasons for transferral to } \\
\text { emergency departments } \\
\text { of terminally ill patients - } \\
\text { a French descriptive and } \\
\text { retrospective study }\end{array}$ & 2016/ França & $\begin{array}{l}\text { Identificar quais razões } \\
\text { levam os pacientes terminais } \\
\text { hospitalizados em casa a } \\
\text { procurar os serviços de } \\
\text { emergência para, assim, } \\
\text { determinar se essas procuras } \\
\text { eram potencialmente } \\
\text { evitáveis. }\end{array}$ & $\begin{array}{l}\text { Quantitativo e } \\
\text { descritivo }\end{array}$ & $\begin{array}{l}\text { Fraqueza generalizada, } \\
\text { dispneia, dor, oclusão e } \\
\text { sangramento. }\end{array}$ \\
\hline
\end{tabular}

Fonte: Dados da pesquisa. 
Quadro 2. Continuação...

\begin{tabular}{|c|c|c|c|c|}
\hline Título & Ano/País & Objetivo (s) & Método & $\begin{array}{c}\text { Principais sinais e } \\
\text { sintomas relacionados à } \\
\text { doença oncológica }\end{array}$ \\
\hline $\begin{array}{l}\text { The effect of weekly } \\
\text { specialist palliative care } \\
\text { teleconsultations in } \\
\text { patients with advanced } \\
\text { cancer-a randomized } \\
\text { clinical trial }{ }^{88}\end{array}$ & 2017/ Holanda & $\begin{array}{l}\text { Determinar se as teleconsultas } \\
\text { semanais, realizadas por } \\
\text { especialistas em cuidados } \\
\text { paliativos domiciliares, } \\
\text { melhoram a carga de sintomas } \\
\text { vivenciados pelo paciente } \\
\text { quando comparadas ao } \\
\text { "atendimento habitual". }\end{array}$ & $\begin{array}{l}\text { Randomizado } \\
\text { e prospectivo } \\
\text { não cego de } \\
\text { dois braços }\end{array}$ & $\begin{array}{l}\text { Sistema de Avaliação dos } \\
\text { Sintomas de Edmonton } \\
\text { (ESAS): dor, fadiga, náusea, } \\
\text { depressão, ansiedade, } \\
\text { sonolência, perda de } \\
\text { apetite e bem-estar, } \\
\text { acrescidos da ansiedade e } \\
\text { depressão. }\end{array}$ \\
\hline $\begin{array}{l}\text { Hospital admission } \\
\text { of cancer patients: } \\
\text { avoidable practice or } \\
\text { necessary care? }\end{array}$ & 2015/Itália & $\begin{array}{l}\text { Descrever as admissões em } \\
\text { um serviço de internação } \\
\text { de oncologia médica no que } \\
\text { diz respeito aos pacientes } \\
\text { e características do tumor } \\
\text { e o resultado da internação } \\
\text { hospitalar. }\end{array}$ & $\begin{array}{l}\text { Quantitativo e } \\
\text { retrospectivo }\end{array}$ & $\begin{array}{l}\text { Dispneia, dor, febre, } \\
\text { obstrução intestinal, } \\
\text { náuseas/vômitos, icterícia, } \\
\text { diarreia, disfagia, fadiga e } \\
\text { caquexia. }\end{array}$ \\
\hline $\begin{array}{l}\text { Sleep disturbances in } \\
\text { patients with advanced } \\
\text { cancer in different } \\
\text { palliative care settings }{ }^{30}\end{array}$ & 2015/Itália & $\begin{array}{l}\text { Avaliar a prevalência de } \\
\text { distúrbios do sono e possíveis } \\
\text { correlações com fatores } \\
\text { associados em um grande } \\
\text { número de pacientes com } \\
\text { câncer avançado internados } \\
\text { em diferentes ambientes de } \\
\text { cuidados paliativos. }\end{array}$ & $\begin{array}{l}\text { Quantitativo e } \\
\text { descritivo }\end{array}$ & $\begin{array}{l}\text { ESAS: dor, astenia, náusea, } \\
\text { anorexia, ansiedade, } \\
\text { depressão, dispneia e } \\
\text { bem-estar. }\end{array}$ \\
\hline $\begin{array}{l}\text { Age differences in } \\
\text { the last week of life } \\
\text { in advanced cancer } \\
\text { patients followed at } \\
\text { home }^{31}\end{array}$ & 2016/Itália & $\begin{array}{l}\text { Avaliar as possíveis diferenças } \\
\text { na carga de sintomas e } \\
\text { nos problemas de dor e a } \\
\text { necessidade de sedação } \\
\text { paliativa, em diferentes faixas } \\
\text { etárias, na última semana de } \\
\text { vida. }\end{array}$ & $\begin{array}{l}\text { Transversal e } \\
\text { retrospectivo }\end{array}$ & $\begin{array}{l}\text { ESAS: dor, náusea, astenia, } \\
\text { ansiedade, depressão, } \\
\text { anorexia, dispneia, } \\
\text { sonolência e bem-estar. }\end{array}$ \\
\hline $\begin{array}{l}\text { Characteristics of } \\
\text { advanced cancer } \\
\text { patients who were } \\
\text { readmitted to an acute } \\
\text { palliative/supportive } \\
\text { care unit }^{32}\end{array}$ & 2017/Itália & $\begin{array}{l}\text { Avaliar as características } \\
\text { dos pacientes readmitidos } \\
\text { em uma unidade de } \\
\text { cuidados paliativos, os } \\
\text { motivos da readmissão e o } \\
\text { desfecho após receberem } \\
\text { a avaliação e o tratamento } \\
\text { especializado. }\end{array}$ & $\begin{array}{l}\text { Observacional } \\
\text { e analítico }\end{array}$ & $\begin{array}{l}\text { ESAS: dor, fraqueza, } \\
\text { náuseas, depressão, } \\
\text { ansiedade, sonolência, } \\
\text { dispneia, insônia, apetite e } \\
\text { bem-estar. }\end{array}$ \\
\hline $\begin{array}{l}\text { Characteristics of } \\
\text { patients with an } \\
\text { unplanned admission to } \\
\text { an acute palliative care } \\
\text { unit }^{33}\end{array}$ & 2017/Itália & $\begin{array}{l}\text { Comparar a carga de } \\
\text { sintomas de pacientes } \\
\text { que tiveram admissão não } \\
\text { planejada em uma unidade } \\
\text { de cuidados paliativos agudos } \\
\text { com pacientes que tiveram } \\
\text { uma admissão planejada } \\
\text { regular. }\end{array}$ & Coorte & $\begin{array}{l}\text { ESAS: dor, fraqueza, } \\
\text { náuseas, depressão, } \\
\text { ansiedade, sonolência, } \\
\text { dispneia, insônia, apetite e } \\
\text { bem-estar. }\end{array}$ \\
\hline
\end{tabular}

Fonte: Dados da pesquisa. 
Quadro 2. Continuação...

\begin{tabular}{|c|c|c|c|c|}
\hline Título & Ano/País & Objetivo (s) & Método & $\begin{array}{c}\text { Principais sinais e } \\
\text { sintomas relacionados à } \\
\text { doença oncológica }\end{array}$ \\
\hline $\begin{array}{l}\text { Prevalence of delirium } \\
\text { in advanced cancer } \\
\text { patients in home } \\
\text { care and hospice and } \\
\text { outcomes after } 1 \text { week of } \\
\text { palliative care }\end{array}$ & 2018/Itália & $\begin{array}{l}\text { Avaliar a prevalência de } \\
\text { delirium em pacientes com } \\
\text { câncer avançado admitidos } \\
\text { em diferentes serviços de } \\
\text { cuidados paliativos na Itália e } \\
\text { possíveis fatores relacionados. }\end{array}$ & $\begin{array}{l}\text { Quantitativo, } \\
\text { estudo } \\
\text { de casos } \\
\text { consecutivos }\end{array}$ & $\begin{array}{l}\text { ESAS: dor, astenia, } \\
\text { náuseas, anorexia, } \\
\text { ansiedade, depressão, } \\
\text { sonolência, dispneia e } \\
\text { bem-estar. }\end{array}$ \\
\hline $\begin{array}{l}\text { Symptom expression } \\
\text { in advanced cancer } \\
\text { patients admitted to } \\
\text { hospice or home care } \\
\text { with and without } \\
\text { delirium }^{35}\end{array}$ & 2018/Itália & $\begin{array}{l}\text { Investigar a relação entre o } \\
\text { delirium e a expressão de } \\
\text { sintomas em pacientes com } \\
\text { câncer avançado internados } \\
\text { em serviços de cuidados } \\
\text { paliativos. }\end{array}$ & $\begin{array}{l}\text { Quantitativo e } \\
\text { prospectivo. }\end{array}$ & $\begin{array}{l}\text { Fraqueza, náusea, } \\
\text { sonolência, falta de } \\
\text { apetite, bem-estar, } \\
\text { depressão e delírio. }\end{array}$ \\
\hline $\begin{array}{l}\text { Do symptoms among } \\
\text { home palliative care } \\
\text { patients with advanced } \\
\text { cancer decide the place } \\
\text { of death? Focusing on } \\
\text { the presence or absence } \\
\text { of symptoms during } \\
\text { home care }\end{array}$ & 2016/Japão & $\begin{array}{l}\text { Investigar a associação } \\
\text { entre o local real da morte } \\
\text { de pacientes japoneses em } \\
\text { tratamento domiciliar com } \\
\text { o câncer avançado e os } \\
\text { fatores individuais, de doença } \\
\text { e ambientais, incluindo a } \\
\text { presença ou a ausência de } \\
\text { sintomas. }\end{array}$ & $\begin{array}{l}\text { Quantitativo e } \\
\text { descritivo }\end{array}$ & $\begin{array}{l}\text { Dor, delírio, depressão e } \\
\text { dispneia. }\end{array}$ \\
\hline $\begin{array}{l}\text { Changes in Relatives' } \\
\text { Perspectives on Quality } \\
\text { of Death, Quality of } \\
\text { Care, Pain Relief, and } \\
\text { Caregiving Burden } \\
\text { Before and After a } \\
\text { Region-Based Palliative } \\
\text { Care Intervention } \\
37\end{array}$ & 2016/Japão & $\begin{array}{l}\text { Examinar as mudanças nos } \\
\text { resultados dos cuidados } \\
\text { paliativos em diferentes } \\
\text { ambientes de cuidados } \\
\text { (hospitais, unidades de } \\
\text { cuidados paliativos e casa) } \\
\text { e obter informações sobre } \\
\text { como melhorar os cuidados } \\
\text { paliativos em nível regional. }\end{array}$ & $\begin{array}{l}\text { Ensaio de } \\
\text { intervenção }\end{array}$ & Dor. \\
\hline $\begin{array}{l}\text { How to come to } \\
\text { terms with facing } \\
\text { death: a qualitative } \\
\text { study examining the } \\
\text { experiences of patients } \\
\text { with terminal cancer } \\
\text { 38 }\end{array}$ & 2019/Japão & $\begin{array}{l}\text { Explorar como os pacientes } \\
\text { com câncer terminal, } \\
\text { que não expressaram } \\
\text { humor deprimido ou dor, } \\
\text { gerenciam os sentimentos } \\
\text { associados à ansiedade e à } \\
\text { depressão. }\end{array}$ & $\begin{array}{l}\text { Qualitativo e } \\
\text { exploratório }\end{array}$ & $\begin{array}{l}\text { Dor física, ansiedade, } \\
\text { depressão, tristeza, bem- } \\
\text { estar e fraqueza. }\end{array}$ \\
\hline $\begin{array}{l}\text { Behavioral risk factors of } \\
\text { constipation in palliative } \\
\text { care patients }^{39}\end{array}$ & 2015/Polônia & $\begin{array}{l}\text { Avaliar a correlação entre a } \\
\text { frequência de evacuações } \\
\text { e os fatores de risco de } \\
\text { constipação. }\end{array}$ & $\begin{array}{l}\text { Coorte, } \\
\text { retrospectivo }\end{array}$ & $\begin{array}{l}\text { Dor, sonolência, náuseas, } \\
\text { vômitos, caquexia e } \\
\text { constipação. }\end{array}$ \\
\hline $\begin{array}{l}\text { Is dying in hospital better } \\
\text { than home in incurable } \\
\text { cancer and what } \\
\text { factors influence this? A } \\
\text { population-based study }{ }^{40}\end{array}$ & $\begin{array}{l}\text { 2015/ Reino } \\
\text { Unido }\end{array}$ & $\begin{array}{l}\text { Verificar a associação entre } \\
\text { o local da morte, os serviços } \\
\text { de saúde utilizados e a } \\
\text { dor, a sensação de paz e a } \\
\text { intensidade do luto. }\end{array}$ & $\begin{array}{l}\text { Estudo de } \\
\text { caso-controle }\end{array}$ & Dor e tristeza. \\
\hline
\end{tabular}

Fonte: Dados da pesquisa. 
Quadro 2. Continuação...

\begin{tabular}{|c|c|c|c|c|}
\hline Título & Ano/País & Objetivo (s) & Método & $\begin{array}{c}\text { Principais sinais e } \\
\text { sintomas relacionados à } \\
\text { doença oncológica }\end{array}$ \\
\hline $\begin{array}{l}\text { What are the current } \\
\text { challenges of managing } \\
\text { cancer pain and could } \\
\text { digital technologies } \\
\text { help? }\end{array}$ & $\begin{array}{l}\text { 2018/ Reino } \\
\text { Unido }\end{array}$ & $\begin{array}{l}\text { Explorar as estratégias } \\
\text { atuais de gerenciamento da } \\
\text { dor usadas por pacientes, } \\
\text { cuidadores e profissionais e } \\
\text { investigar as oportunidades } \\
\text { de tecnologias digitais para } \\
\text { aprimorar o gerenciamento da } \\
\text { dor no câncer. }\end{array}$ & Qualitativo & $\begin{array}{l}\text { Dor, prisão de ventre, } \\
\text { alucinações e efeitos } \\
\text { colaterais urinários. }\end{array}$ \\
\hline $\begin{array}{l}\text { Factors associated with } \\
\text { emergency services use } \\
\text { in Taiwanese advanced } \\
\text { cancer patients receiving } \\
\text { palliative home care } \\
\text { services during out- } \\
\text { of-hours periods: a } \\
\text { retrospective medical } \\
\text { record study }\end{array}$ & 2018/ Taiwan & $\begin{array}{l}\text { Investigar os fatores para } \\
\text { o uso do departamento de } \\
\text { emergência pelos pacientes } \\
\text { com câncer avançado nos } \\
\text { períodos fora do expediente } \\
\text { do serviço de cuidados } \\
\text { paliativos domiciliares. }\end{array}$ & $\begin{array}{l}\text { Caso-controle } \\
\text { baseado } \\
\text { em revisão } \\
\text { retrospectiva. }\end{array}$ & $\begin{array}{l}\text { Dor, febre, náuseas/ } \\
\text { vômitos, constipação, } \\
\text { dispneia, mudança de } \\
\text { consciência e sangramento } \\
\text { gastrointestinal. }\end{array}$ \\
\hline $\begin{array}{l}\text { A Prospective Cohort } \\
\text { Study of Factors } \\
\text { Associated With Place of } \\
\text { Death Among Patients } \\
\text { With Late-Stage Cancer } \\
\text { in Southern Africa }{ }^{43}\end{array}$ & $\begin{array}{l}\text { 2019/ África do } \\
\text { Sul }\end{array}$ & $\begin{array}{l}\text { Investigar os fatores } \\
\text { associados ao local preferido } \\
\text { e real de morte para pacientes } \\
\text { com câncer em Joanesburgo, } \\
\text { África do Sul. }\end{array}$ & $\begin{array}{l}\text { Coorte } \\
\text { prospectivo }\end{array}$ & Dor. \\
\hline $\begin{array}{l}\text { An examination of home- } \\
\text { based end-of-life care } \\
\text { for cancer patients: a } \\
\text { qualitative study }{ }^{44}\end{array}$ & 2019/China & $\begin{array}{l}\text { Explorar como os cuidados } \\
\text { de fim de vida domiciliares } \\
\text { são prestados em centros } \\
\text { de serviços de saúde } \\
\text { comunitários em Xangai e } \\
\text { examinar as dificuldades } \\
\text { durante a prestação desses } \\
\text { cuidados. }\end{array}$ & Qualitativo & Dor. \\
\hline $\begin{array}{l}\text { Intervention of } \\
\text { Humanized Nursing } \\
\text { Accompaniment and } \\
\text { Quality of Life in People } \\
\text { with Advanced Cancer }\end{array}$ & 2019/Chile & $\begin{array}{l}\text { Avaliar o efeito de } \\
\text { uma intervenção de } \\
\text { acompanhamento humanizado } \\
\text { de Enfermagem em domicílio } \\
\text { na qualidade de vida das } \\
\text { pessoas com câncer avançado } \\
\text { e do cuidador familiar. }\end{array}$ & $\begin{array}{l}\text { Pré- } \\
\text { experimental } \\
\text { de pré e pós- } \\
\text { intervenção. }\end{array}$ & $\begin{array}{l}\text { Fadiga, dispneia, falta } \\
\text { de apetite, constipação, } \\
\text { diarreia, insônia, anorexia, } \\
\text { náusea/vômito e dor. }\end{array}$ \\
\hline
\end{tabular}

Fonte: Dados da pesquisa.

Apesar da proximidade apresentada entre a variação de itens nos dois subgrupos, destaca-se que, quando comparados em relação ao número de vezes em que foram mencionados, pelo menos, uma vez nos artigos selecionados, os itens do subgrupo dos sintomas apareceram 184 (65,9\%) vezes, enquanto os itens do subgrupo dos sinais foram mencionados $95(34,1 \%)$ vezes.

\section{DISCUSSÃO}

A identificação dos principais sinais e sintomas manifestados pela população destacada neste estudo pode orientar a prática dos profissionais de saúde responsáveis pelas consultas em programas de assistência domiciliar em cuidados paliativos oncológicos. Gerenciar os sintomas físicos e psicológicos dos 


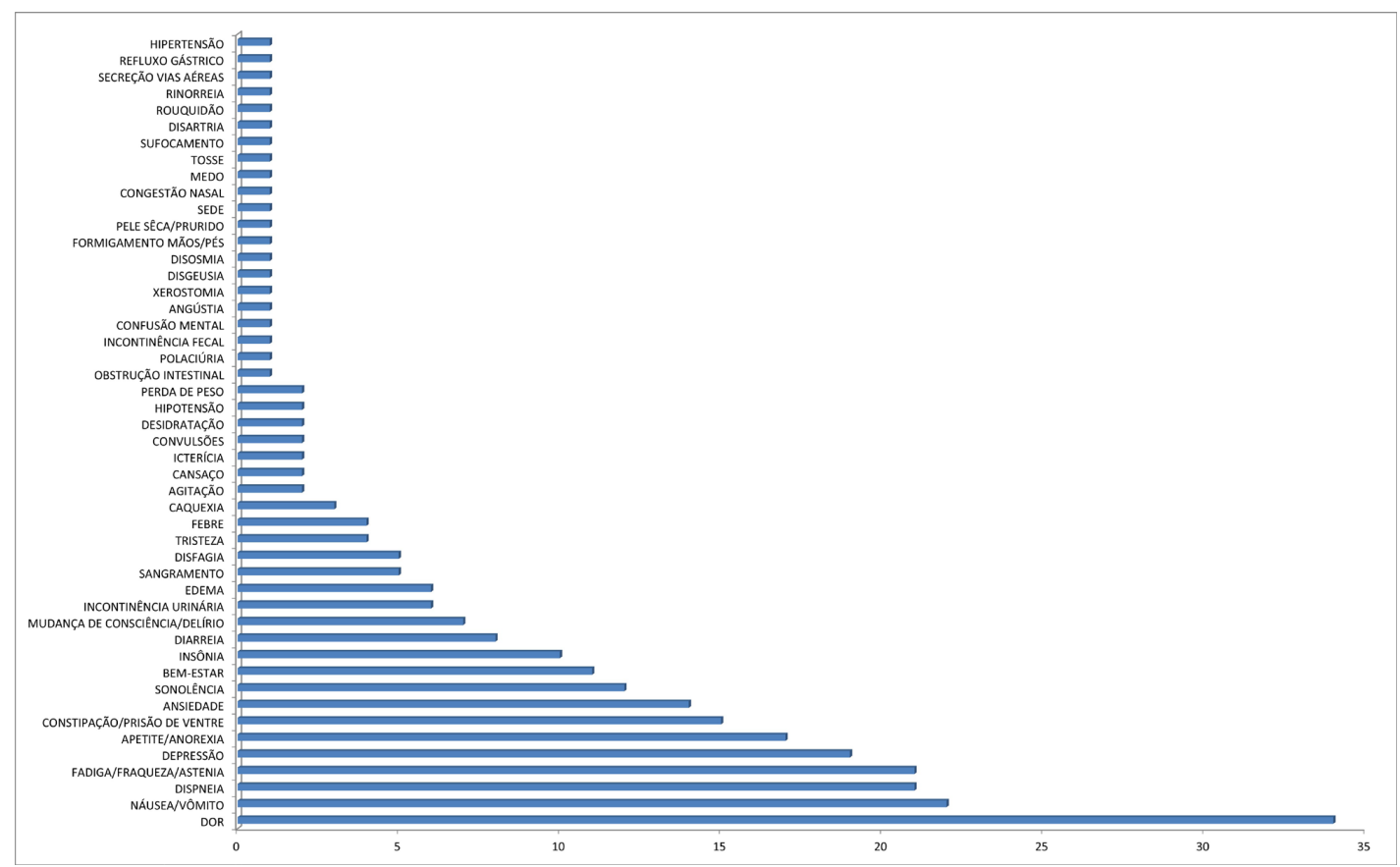

Figura 2. Lista dos 48 sinais e sintomas mencionados nos 35 artigos. Rio de Janeiro, Brasil, 2020. Fonte: Dados da pesquisa.

Quadro 3. Classificação dos subgrupos dos sinais e sintomas mencionados nos 35 artigos. Rio de Janeiro, Brasil, 2020.

\begin{tabular}{|cc|}
\hline SINAIS & SINTOMAS \\
\hline Náusea/Vômito & Dor \\
Sonolência & Dispneia \\
Diarreia & Fadiga/Fraqueza/Astenia \\
Incontinência urinária & Depressão \\
Mudança de consciência/ Delírio & Ansiedade \\
Edema & Constipação/Prisão de ventre \\
Sangramento & Falta de Apetite/Anorexia \\
Febre & Bem-estar \\
Caquexia & Insônia \\
Agitação & Disfagia \\
Icterícia & Tristeza \\
Convulsões & Cansaço \\
Desidratação & Obstrução intestinal \\
Hipotensão & Polaciúria \\
Perda de peso & Angústia \\
Incontinência fecal & Xerostomia \\
Confusão mental & Disgeusia \\
Pele seca com prurido & Disosmia \\
Tosse & Formigamento mãos/pés \\
Disartria & Sede \\
Rouquidão & Congestão nasal \\
Rinorreia & Medo \\
Secreção nas vias aéreas & Sufocamento \\
Refluxo gástrico & \\
Hipertensão & \\
\hline
\end{tabular}

Fonte: Dados da pesquisa. 
pacientes é de substancial importância, sendo esta a principal conduta da equipe paliativa, que deve ser envolvida na linha do cuidado do paciente com câncer de forma precoce, de modo a prevenir complicações e a proporcionar a melhora da qualidade de vida, além de fornecer suporte e reduzir a sobrecarga dos cuidadores ${ }^{7,12,17-19,25,29}$.

As evidências apontam que os pacientes com câncer avançado apresentam complicações concomitantes ou sintomas não controlados durante todo o curso da doença $a^{17,22,33}$. Embora o controle total dos sintomas nem sempre seja possível, sua abordagem ineficaz no domicílio tem sido motivo de atendimentos em centros de emergência, descontinuando a $A D$ e prejudicando a qualidade do plano assistencial dos $\mathrm{CPE}^{22}$. Os serviços de assistência domiciliar precisam organizar a rotina das consultas, priorizando os pacientes em processo de morrer, pois a proximidade da morte aumenta o sofrimento e a carga de sintomas $19,22,29,31$.

A AD, se bem organizada e estruturada, pode evitar o uso dos centros de emergência e contribuir para a otimização de leitos hospitalares, reintegrando o paciente ao núcleo familiar, preservando a sua autonomia e buscando a sua independência funcional ${ }^{7,16}$. Mas se ratifica, nesta revisão, que a prestação do CP em casa depende, em grande parte, dos cuidadores familiares, e a falta de informações referentes a eles pode limitar os estudos sobre esta temática, o que ocorre principalmente nos delineamentos metodológicos retrospectivos, como os que constam na amostra selecionada ${ }^{12,19,24,29}$.

Um sintoma, gerenciado de forma inadequada, pode interferir negativamente no desenvolvimento ou agravamento de outro sintoma ${ }^{19}$. Os sintomas mais citados, nos diferentes estudos, devem ser avaliados no que se refere às suas causas, pois podem ser primários ao câncer ou secundários a outros fatores e serem reversíveis ou não ${ }^{18}$. Além disso, a maior representatividade dos sintomas em número de vezes em que foram mencionados nos estudos selecionados indica que os profissionais de saúde precisam estar atentos à comunicação eficaz com pacientes e familiares, uma vez que, como dados subjetivos, requerem atenção e sensibilidade para melhor identificá-los, estabelecer fatores relacionados e melhor agir ${ }^{11,20,30,38}$.

Atenta-se, por exemplo, que o controle inadequado da dor está relacionado, dentre outros fatores, à dificuldade dos profissionais em medirem adequadamente a queixa; assim como é indicada a avaliação do estado mental dos pacientes com base em suas narrações, para além de escala, considerando o destaque do sintoma de depressão ${ }^{13,17,38}$. O manejo desses sintomas requer o acompanhamento contínuo devido à gravidade e à necessidade de frequentes avaliações como no caso da dor, que pode requerer alterações de tipo e dose de medicamentos ${ }^{27,41}$.

Importa destacar que, neste estudo, a maioria dos artigos selecionados apresentou metodologia quantitativa, o que indica a possibilidade de limitações na compreensão dos fenômenos. Nesta revisão, a relevância dos sintomas em relação aos sinais e a evidência da influência das questões psicológicas e emocionais na potencialização dos sintomas físicos ${ }^{11-14,18,20,30,38}$ apontam para a necessidade de pesquisas de abordagens mistas para melhor compreender o caráter subjetivo do que é sentido e manifestado por cada paciente em diferentes realidades.

Assim, identificar a dor como o sintoma mais mencionado nos estudos selecionados encaminha para a necessidade de instituir tecnologias assistenciais que possam orientar as práticas profissionais para o adequado controle deste sintoma, assim como de todos os outros destacados nesta revisão, valorizando também a educação em saúde para ajudar o paciente e a família a identificá-los o mais precocemente possível e acompanhar a resposta às terapêuticas ${ }^{24,41}$.

Para o auxílio no gerenciamento dos sintomas de pacientes com câncer avançado, a literatura destacou o ESAS, que abrange os sintomas físicos e psicológicos como dor, fadiga, náusea, depressão, ansiedade, sonolência, insônia, apetite, bem-estar e falta de ar. Trata-se, portanto, de importante ferramenta para guiar os profissionais da saúde no planejamento assistencial a estes pacientes ${ }^{7,19,25,28,30-34}$

O cenário do domicílio deve ser um alerta aos profissionais para a possibilidade de o paciente manifestar, de forma mais intensa, determinados sintomas, como apontam os estudos ao retratar a constipação, a ansiedade e a depressão. No caso da constipação, os pacientes atendidos no domicílio são muito mais acamados em comparação aos pacientes hospitalizados, o que contribui para o seu desenvolvimento, que parece ser uma das causas não resolvidas do sofrimento desses pacientes, de difícil tratamento ${ }^{39}$. E no caso da ansiedade e da depressão, em casa, somadas à necessidade de cuidados dos familiares, esses pacientes sofrem pesar por terem desenvolvido a doença, uma das principais fontes de crise e sentimentos associados à conscientização do prognóstico e à aproximação da morte ${ }^{30,38}$.

A partir da identificação dos principais sinais e sintomas, que comprometem o estado físico, psicológico e emocional do paciente, prejudicando o seu bem-estar, é importante que sejam estabelecidos cuidados para o seu controle, minimizando o sofrimento dessas pessoas e de suas famílias ${ }^{18,20,29}$. Contudo, lidar com os sinais e sintomas angustiantes, manifestados por pacientes com câncer avançado, e promover CP de qualidade, incluindo o contexto do domicílio, dependem, principalmente, de profissionais de saúde treinados e capacitados. Desse modo, os resultados desta RIL podem direcionar ações de formação profissional e educação permanente, contemplando este tema de grande relevância ${ }^{46}$.

\section{CONCLUSÃO E IMPLICAÇÕES PARA A PRÁTICA}

Nesta RIL, foi identificada uma grande variedade de sinais e sintomas que podem ser manifestados por pacientes em cuidados paliativos oncológicos no domicílio. A partir da contagem do número de vezes em que foram mencionados, pelo menos, uma vez nos artigos selecionados, puderam-se identificar os mais comuns, de modo a direcionar a atenção dos profissionais para as intervenções mais adequadas e o mais precocemente 
possível, o que contribui para viabilizar a $A D$, considerando o desafio de tratar-se de um ambiente não controlado.

A presença de sintomas não controlados gera prejuízo na qualidade de vida, enquanto o manejo adequado melhora o bem-estar dos pacientes com câncer em CP. Na prática, o controle dos sintomas na assistência domiciliar pode auxiliar nos indicadores de qualidade da assistência e de morte no domicílio. Assim, é preciso ter atenção à necessidade de formação profissional e educação permanente para o alcance deste objetivo, instrumentalizando os profissionais para a prática baseada nas melhores evidências e para a educação em saúde.

Salienta-se que, para minimizar os vieses, como o de seleção, foram empregadas estratégias para diminuir a perda de possíveis estudos elegíveis nas bases de dados investigadas, como a seleção de artigos em três idiomas, incluindo o inglês como língua universal, e o acesso às bases pelo Portal de Periódicos Capes. Destaca-se ainda que, em todo o processo de seleção da amostra e extração de dados, se trabalhou com mais de uma pesquisadora para minimizar erros na interpretação.

Este estudo demonstrou a necessidade de próximos passos na pesquisa relacionados à identificação e ao manejo adequado dos sinais e sintomas manifestados por pacientes em cuidados paliativos oncológicos na assistência domiciliar, bem como acerca de fatores associados ao uso das emergências e da morte no domicílio.

\section{CONTRIBUIÇÕES DOS AUTORES}

Concepção e planejamento da proposta de revisão. Nair Caroline Cavalcanti de Mendonça Bittencourt. Marcelle Miranda da Silva.

Busca das fontes bibliográficas. Nair Caroline Cavalcanti de Mendonça Bittencourt. Karoliny Alves Santos.

Análise de dados. Nair Caroline Cavalcanti de Mendonça Bittencourt. Karoliny Alves Santos. Maria Gefé da Rosa Mesquita. Vanessa Gomes da Silva. Audrei Castro Telles. Marcelle Miranda da Silva.

Interpretação de dados. Nair Caroline Cavalcanti de Mendonça Bittencourt. Karoliny Alves Santos. Maria Gefé da Rosa Mesquita. Vanessa Gomes da Silva. Audrei Castro Telles. Marcelle Miranda da Silva.

Redação e revisão crítica do manuscrito. Nair Caroline Cavalcanti de Mendonça Bittencourt. Karoliny Alves Santos. Maria Gefé da Rosa Mesquita. Vanessa Gomes da Silva. Audrei Castro Telles. Marcelle Miranda da Silva.

Aprovação da versão final do conteúdo a ser publicado. Nair Caroline Cavalcanti de Mendonça Bittencourt. Karoliny Alves Santos. Maria Gefé da Rosa Mesquita. Vanessa Gomes da Silva. Audrei Castro Telles. Marcelle Miranda da Silva.

Concordância em responsabilizar-se por todos os aspectos do trabalho assegurando que questões relacionadas a acurácia ou integridade de quaisquer partes do trabalho serão adequadamente investigadas e resolvidas. Nair Caroline Cavalcanti de Mendonça Bittencourt. Karoliny Alves Santos. Maria Gefé da Rosa Mesquita. Vanessa Gomes da Silva. Audrei Castro Telles. Marcelle Miranda da Silva.

\section{EDITOR ASSOCIADO}

Rodrigo Nogueira da Silva (D)

\section{EDITOR CIENTÍFICO}

\author{
Ivone Evangelista Cabral (D)
}

\section{REFERÊNCIAS}

1. Instituto Nacional de Câncer José Alencar Gomes da Silva - INCA Estimativa 2020: incidência de câncer no Brasil [Internet]. Rio de Janeiro: INCA; 2019 [citado 2020 maio 25]. Disponível em: https://www.inca. gov.br/sites/ufu.sti.inca.local/files//media/document/estimativa-2020incidencia-de-cancer-no-brasil.pdf

2. World Health Organization - WHO. Worldwide Palliative Care Alliance Global Atlas of Palliative Care at the End of Life. Geneve: WHO 2014 [citado 2020 abr 25]. Disponível em: https://www.who.int/nmh/ Global_Atlas_of_Palliative_Care.pdf

3. Oliveira MBP, Souza NR, Bushatsky M, Dâmaso BFR, Bezerra DM, Brito JA. Oncological homecare: family and caregiver perception of palliative care. Esc Anna Nery. 2017;21(2):e20170030. http://dx.doi. org/10.5935/1414-8145.20170030.

4. Instituto Nacional de Câncer José Alencar Gomes da Silva - INCA. ABC do câncer: abordagens básicas para o controle do câncer [Internet]. $5^{\text {a }}$ ed. Rio de Janeiro: INCA; 2019 [citado 2020 maio 10]. Disponível em: https://www.inca.gov.br/sites/ufu.sti.inca.local/files//media/document/ livro-abc-5- edicao_1.pdf

5. Matos MR, Muniz RM, Barboza MCN, Viegas AC, Rockembach JA, Lindemann LG. Representações sociais do processo de adoecimento dos pacientes oncológicos em cuidados paliativos no domicílio. Rev Enferm UFSM. 2017;7(3):398-410. http://dx.doi.org/10.5902/2179769225801.

6. Verhoef MJ, de Nijs E, Horeweg N, Fogteloo J, Heringhaus C, Jochems A et al. Palliative care needs of advanced cancer patients in the emergency department at the end of life: an observational cohort study. Support Care Cancer. 2020;28(3):1097-107. http://dx.doi.org/10.1007/ s00520-019-04906-x. PMid:31197539.

7. Heins M, Hofstede J, Rijken M, Korevaar J, Donker G, Francke A. Palliative care for patients with cancer: do patients receive the care they consider important? A survey study. BMC Palliat Care. 2018;17(1):61. http://dx.doi.org/10.1186/s12904-018-0315-3. PMid:29665807.

8. Mendes KS, Silveira RCCP, Galvão CM. Revisão integrativa: método de pesquisa para a incorporação de evidências na saúde e na enfermagem. Texto Contexto Enferm. 2008 dez;17(4):758-64. http://dx.doi.org/10.1590/ S0104-07072008000400018

9. Lockwood C, Porritt K, Munn Z, Rittenmeyer L, Salmond S, Bjerrum $M$ et al. Systematic reviews of qualitative evidence. In: Aromataris $E$, Munn Z, editors. JBI manual for evidence synthesis. USA: JBI; 2020. Chap. 2. http://dx.doi.org/10.46658/JBIMES-20-03

10. Whittemore $R$, Knafl $K$. The integrative review: updated methodology J Adv Nurs. 2005 dez;52(5):546-53. http://dx.doi.org/10.1111/j.13652648.2005.03621.x. PMid:16268861.

11. Silva AC, Rudge AM. Construindo a noção de sintoma: articulações entre psicanálise e pragmática. Psicol USP. 2017;28(2):224-9. http:// dx.doi.org/10.1590/0103-656420160051.

12. Krug K, Miksch A, Peters-Klimm F, Engeser P, Szecsenyi J. Correlation between patient quality of life in palliative care and burden of their family caregivers: a prospective observational cohort study. BMC Palliat Care. 2016 jan;15:4. http://dx.doi.org/10.1186/s12904-016-0082-y. PMid:26767785.

13. Küttner $\mathrm{S}$, Wüller J, Pastrana T. How much psychological distress is experienced at home by patients with palliative care needs in Germany? A cross-sectional study using the distress thermometer. Palliat Support Care. 2017 abr;15(2):205-13. http://dx.doi.org/10.1017/ S1478951516000560. PMid:27456895.

14. Kaiser F, Rudloff LV, Vehling-Kaiser U, Hollburg W, Nauck F, Alt-Epping B. Palliative home care for patients with advanced haematological 
malignancies-a multicenter survey. Ann Hematol. 2017;96(9):1557-62. http://dx.doi.org/10.1007/s00277-017-3045-3. PMid:28638954.

15. Duval PA, Bergmann RB, Vale IAV, Colling C, Araújo ES, Assunção MCF. Prevalência de caquexia neoplásica e fatores associados na internação domiciliar. Rev bras cancerol. 2015 jul;61(3):261-7. http:// dx.doi.org/10.32635/2176-9745.RBC.2015v61n3.262.

16. Faller JW, Zilly A, de Moura CB, Brusnicki PH. Multidimensional pain and symptom assessment scale for elderly people in palliative care. Cogitare enferm. 2016 abr/jun;21(2):1-9. http://dx.doi.org/10.5380/ ce.v21i2.45734.

17. Miranda B, Vidal SA, Mello MJ, Lima JT, Rêgo JC, Pantaleão MC et al. Cancer patients, emergencies service and provision of palliative care. Rev Assoc Med Bras. 2016 maio/jun;62(3):207-11. http://dx.doi. org/10.1590/1806-9282.62.03.207. PMid:27310542.

18. Tomaszewski AS, Oliveira SG, Arrieira ICO, Cardoso DH, Sartor SF. Demonstrations and necessities on the death and dying process: perspective of the person with cancer. J Res fundam. care online. 2017 jul/set;9(3):705-16. http://dx.doi.org/10.9789/2175-5361.rpcfo.v9.5503.

19. Scottini MA, Moritz RD, Siqueira JE. Cognition, functionality and symptoms in patients under home palliative care. Rev Assoc Med Bras. 2018 jan;64(10):922-7. http://dx.doi.org/10.1590/1806-9282.64.10.922. PMid:30517240.

20. Freeman S, Hirdes JP, Stolee P, Garcia J, Smith TF. Correlates and predictors of changes in dyspnea symptoms over time among communitydwelling palliative home care clients. J Pain Symptom Manage. 2015 dez;50(6):793-805. http://dx.doi.org/10.1016/j.jpainsymman.2015.06.016. PMid:26297850.

21. Bainbridge $D$, Seow $H$. Palliative care experience in the last 3 months of life: a quantitative comparison of care provided in residential hospices, hospitals, and the home from the perspectives of bereaved caregivers. Am J Hosp Palliat Care. 2018;35(3):456-63. http://dx.doi. org/10.1177/1049909117713497. PMid:28610431.

22. Alsirafy SA, Raheem AA, AI-Zahrani AS, Mohammed AA, Sherisher MA, El-Kashif AT et al. Emergency department visits at the end of life of patients with terminal cancer: pattern, causes, and avoidability. Am J Hosp Palliat Care. 2016;33(7):658-62. http://dx.doi.org/10.1177/1049909115581819. PMid:25877944.

23. O'Neil DS, Prigerson HG, Mmoledi K, Sobekwa M, Ratshikana-Moloko M, Tsitsi JM et al. Informal caregiver challenges for advanced cancer patients during end-of-life care in Johannesburg, South Africa and distinctions based on place of death. J Pain Symptom Manage. 2018;56(1):98-106 http://dx.doi.org/10.1016/j.jpainsymman.2018.03.017. PMid:29604380.

24. Han CJ, Chi NC, Han S, Demiris G, Parker-Oliver D, Washington K et al Communicating caregivers' challenges with cancer pain management: an analysis of home hospice visits. J Pain Symptom Manage. 2018;55(5):1296303. http://dx.doi.org/10.1016/j.jpainsymman.2018.01.004. PMid:29360571.

25. Lage DE, Nipp RD, D'Arpino SM, Moran SM, Johnson PC, Wong RL et al Predictors of posthospital transitions of care in patients with advanced cancer. J Clin Oncol. 2018;36(1):76-82. http://dx.doi.org/10.1200/ JCO.2017.74.0340. PMid:29068784.

26. Setla J, Pasniciuc SV. Home palliative sedation using phenobarbital suppositories: time to death, patient characteristics, and administration protocol. Am J Hosp Palliat Care. 2019;36(10):871-6. http://dx.doi. org/10.1177/1049909119839695. PMid:30947512.

27. Cornillon P, Loiseau S, Aublet-Cuvelier B, Guastella V. Reasons for transferal to emergency departments of terminally ill patients - a French descriptive and retrospective study. BMC Palliat Care. 2016;15(1):87. http://dx.doi.org/10.1186/s12904-016-0155-y. PMid:27769258.

28. Hoek PD, Schers HJ, Bronkhorst EM, Vissers KCP, Hasselaar JGJ. The effect of weekly specialist palliative care teleconsultations in patients with advanced cancer -a randomized clinical trial. BMC Med.2017;15(1):119. http://dx.doi.org/10.1186/s12916-017-0866-9. PMid:28625164.

29. Numico G, Cristofano A, Mozzicafreddo A, Cursio OE, Franco P, Courthod $\mathrm{G}$ et al. Hospital admission of cancer patients: avoidable practice or necessary care? PLoS One. 2015;10(3):e0120827. http:// dx.doi.org/10.1371/journal.pone.0120827. PMid:25812117.

30. Mercadante S, Aielli F, Adile C, Ferrera P, Valle A, Cartoni C et al. Sleep disturbances in patients with advanced cancer in different palliative care settings. J Pain Symptom Manage. 2015;50(6):786-92. http://dx.doi. org/10.1016/j.jpainsymman.2015.06.018. PMid:26311122.
31. Mercadante S, Aielli F, Masedu F, Valenti M, Verna L, Porzio G. Age differences in the last week of life in advanced cancer patients followed at home. Support Care Cancer. 2016;24(4):1889-95. http://dx.doi. org/10.1007/s00520-015-2988-y. PMid:26471279.

32. Mercadante S, Adile C, Ferrera P, Casuccio A. Characteristics of advanced cancer patients who were readmitted to an acute palliative/ supportive care unit. Support Care Cancer. 2017;25(6):1947-52. http:// dx.doi.org/10.1007/s00520-017-3604-0. PMid:28161787.

33. Mercadante S, Adile C, Ferrera P, Casuccio A. Characteristics of patients with an unplanned admission to an acute palliative care unit. Intern Emerg Med. 2017;12(5):587-92. http://dx.doi.org/10.1007/s11739017-1619-7. PMid:28160235.

34. Mercadante S, Masedu F, Balzani I, De Giovanni D, Montanari L, Pittureri $\mathrm{C}$ et al. Prevalence of delirium in advanced cancer patients in home care and hospice and outcomes after 1 week of palliative care Support Care Cancer. 2018;26(3):913-9. http://dx.doi.org/10.1007/ s00520-017-3910-6. PMid:28980071.

35. Mercadante S, Masedu F, Maltoni M, De Giovanni D, Montanari L, Pittureri $C$ et al. Symptom expression in advanced cancer patients admitted to hospice or home care with and without delirium. Intern Emerg Med. 2019;14(4):515-20. http://dx.doi.org/10.1007/s11739-018-1969-9. PMid:30334235.

36. Okamoto Y, Fukui S, Yoshiuchi K, Ishikawa T. Do symptoms among home palliative care patients with advanced cancer decide the place of death? Focusing on the presence or absence of symptoms during home care. J Palliat Med. 2016;19(5):488-95. http://dx.doi.org/10.1089/ jpm.2015.0184. PMid:26849084

37. Maeda I, Miyashita M, Yamagishi A, Kinoshita H, Shirahige Y, Izumi N et al. Changes in Relatives' Perspectives on Qualit of Death, Quality of Care, Pain Relief, and Caregiving Burden Before and After a Region-Based Palliative Care Intervention. J Pain Symptom Manage. 2016:52(5):637-45. http://dx.doi.org/10.1016/j.jpainsymman.2016.03.022. PMid:27664834

38. Kyota A, Kanda K. How to come to terms with facing death: a qualitative study examining the experiences of patients with terminal cancer. BMC Palliat Care. 2019;18(1):33. http://dx.doi.org/10.1186/s12904-019-04176. PMid:30947725.

39. Dzierżanowski T, Cialkowska-Rysz A. Behavioral risk factors of constipation in palliative care patients. Support Care Cancer. 2015;23(6):1787-93. http://dx.doi.org/10.1007/s00520-014-2495-6. PMid:25471176.

40. Gomes B, Calanzani N, Koffman J, Higginson IJ. Is dying in hospital better than home in incurable cancer and what factors influence this? A population-based study. BMC Med. 2015;13:235. http://dx.doi. org/10.1186/s12916-015-0466-5. PMid:26449231.

41. Adam R, de Bruin M, Burton CD, Bond CM, Giatsi Clausen M, Murchie P. What are the current challenges of managing cancer pain and could digital technologies help? BMJ Support Palliat Care. 2018;8(2):204-12. http://dx.doi.org/10.1136/bmjspcare-2016-001232. PMid:28554888.

42. KaoYH, LiuYT, Koo M, Chiang JK. Factors associated with emergency services use in Taiwanese advanced cancer patients receiving palliative home care services during out-ofhours periods: a retrospective medical record study. BMC Palliat Care. 2018;17(1):46. http://dx.doi.org/10.1186/ s12904-018-0302-8. PMid:29530021.

43. Blanchard CL, Ayeni O, O'Neil DS, Prigerson HG, Jacobson JS, Neugut Al et al. A prospective cohort study of factors associated with place of death among patients with late-stage cancer in Southern Africa. $J$ Pain Symptom Manage. 2019;57(5):923-32. http://dx.doi.org/10.1016/j. jpainsymman.2019.01.014. PMid:30708125.

44. Lai XB, Chen LQ, Chen SH, Xia HO. An examination of home-based end-of-life care for cancer patients: a qualitative study. BMC Palliat Care. 2019;18(1):115. http://dx.doi.org/10.1186/s12904-019-0501-y. PMid:31843006.

45. Hermosilla-Ávila AE, Sanhueza-Alvarado OI. Intervention of humanized nursing accompaniment and quality of life in people with advanced cancer Aquichan. 2019;19(3):e1933. http://dx.doi.org/10.5294/aqui.2019.19.3.3.

46. Abu-Odah $\mathrm{H}$, Molassiotis A, Liu J. Challenges on the provision of palliative care for patients with cancer in low- and middle-income countries: a systematic review of reviews. BMC Palliat Care. 2020;19(1):55. http:// dx.doi.org/10.1186/s12904-020-00558-5. PMid:32321487. 